\title{
Retardamento da brotação das batatas durante a armazenagem
}

\author{
HEITOR W. S. MONTENEGRO
}

Assistente-técnico da Cadelra de Horticultura da E. S. A.

"Luiz de Queiroz"

INDICE

Introduçắo $\ldots \ldots \ldots \ldots \ldots \ldots \ldots \ldots \ldots, 76$

Resultadas ...................... 77

Podem-se aproveitar as tubérculos traiados para sementes ? .............. 80

Conclussões $\ldots \ldots \ldots \ldots \ldots \ldots \ldots \ldots \ldots, 81$ 


\section{INTRODUÇAO}

Como é de conhecimento de todos, as batatas, quando são armazenadas para consumo e este demora por alguns meses, começam por murchar e emitir brotos que muito a depreciam tanto no pêso, pois perdem cêrca de 10 a $15 \%$, como em qualidade.

Para evitar esse grande inconveniente, foram feitas pesquisas nos Estados Unidos. Descobriu-se, inicialmente, que a presença de maçăs maduras nos depósitos de batatas, evitava a brotaçăo destas. Investigada pasteriormente a causa, verificou-se ser devido ao desprendimento de gás etileno durante as fases de maturação das mạ̧ás. Outros produtas também possuem esta ação.

Mais tarde foi descoberto que se tratando as batatas com certos hormônios em concentraçóes mais elevadas, êstes evitavam aquela brotaçăo prejudicial.

Estas experiências foram continuadas na Holanda e obtiveram pleno exito. O hormonio utilizado fol o éster metilico do ácido alfanaftalenoacético misturado com talco a 1\%. Aplicam-se 100 grs. deste pó, portanto $1 \mathrm{gr}$. de homónio por hectolitro (cerca de $70 \mathrm{kgs}$.) de batatas.

A vantagem do éster metilico do ácido alfanaftalenoacético é que sendo um líquido que se volatiliza lentamente, vai exercer influência sóbre as gemas das batatas por inacessiveis que estejam.

A pedido do Dr. Gerbatin, representante no Brasil da N. V. Amsterdamsche Chininefabriek, resolvemas fazer algumas experiências com aquele hormônio, já misturado com talco na concentração de 1\%, sob a denominação de Agermina. 
Para um perfeito contrôle, fizemos, em terras da Secção de Horticultura, uma plantação de batatinhas, cuja colheita fol feita em 22 de Abril de 1948.

Em 22 de Junho de 1948, delas pesamos $20 \mathrm{kgs}$. submetendo-as ao seguinte tratamento : $28 \mathrm{grs}$. de Argemina ou 0,20 grs. de éster metillico do ácido alfanaftalenoacético, foram polk:lhados uniformemente sôbre elas.

Deixamas, como testemunha, também $20 \mathrm{kgs}$. de batatas da mesma colheita.

Os dois lotes colocados em caixões, foram pastos no fruteiro de nossa Seç̧áo. e bem arejado; déste modo, nele a temperatura não se eleva demasiadamente.

\section{RESULTADOS :}

Após 80 (oitenta) dias, em 9-9-948, flzemas o exame dos dois lotes. A diferença entre as mesmos era tăo grande que ninguem, dentre as pessoas chamadas para abservar, pôs em duvida a eficácia do produto.

Se bem que o lote tratado também estivesse brotado, naturalmente isso se deu em bem menor escala, como veremos abaixo. A causa déste brotamènto, julgamas' ter sido a demora em realizarmos a aplicaçáo, que so fol felta 2 meses após a colheita. Isto será objeto de nova experiência.

Para que não pairassem dúvidas sôbre os resultados, fizemos a análise estatistica.

Das dois lotes retiramos, ao acaso, $1 \mathrm{~kg}$. e 300 grs. de batatinhas, ou seja, do lote tratado 69 batatinhas e do lote testemunha 59.

A média do $n$. de brotos por batata foi, no lote tratado, 2,06 e no lote testemunha, 4,49. 
O QUADRO ESTATISTICO NOS DEU O SEGUINTE :

\section{Lote tratado}

\begin{tabular}{|c|c|c|c|c|c|}
\hline $\mathbf{v}$ & $\mathbf{f}$ & $\mathrm{fv}$ & v2 & fv2 & \multirow{8}{*}{$\begin{array}{l}\overline{\mathrm{V}_{2}}=2.06 \\
\sigma_{2}= \pm 1,17\end{array}$} \\
\hline 0 & 1 & 0 & 0 & 0 & \\
\hline 1 & 26 & 26 & 1 & 26 & \\
\hline 2 & 22 & 44 & 4 & 88 & \\
\hline 3 & 12 & 36 & 9 & 108 & \\
\hline 4 & 4 & 16 & 16 & 64 & \\
\hline 5 & 4 & 20 & 25 & 100 & \\
\hline & 69 & 142 & & 386 & \\
\hline
\end{tabular}




\section{Lote testemunha}

\begin{tabular}{|c|c|c|c|c|c|}
\hline$\nabla$ & $\mathbf{f}$ & fv & $\mathbf{\nabla 2}$ & fv2 & \\
\hline 0 & 0 & 0 & 0 & 0 & \\
\hline 1 & 3 & 3 & 1 & 3 & \\
\hline 2 & 4 & 8 & 4 & 16 & \\
\hline 3 & 14 & 42 & 9 & 126 & \\
\hline 4 & 10 & 40 & 16 & 160 & $\overline{V_{1}}=4,49$ \\
\hline 5 & 7 & 35 & 25 & 175 & $\sigma_{1}= \pm 1,85$ \\
\hline 6 & 13 & 78 & 36 & 468 & \\
\hline 7 & 6 & 42 & 49 & 294 & \\
\hline 8 & 1 & 8 & 64 & 64 & \\
\hline 9 & 1 & 9 & 81 & 81 & \\
\hline & 59 & 265 & & 1387 & \\
\hline
\end{tabular}

Para comparar as duas médias fizemas um teste $\delta$ Obtivemos :

$$
\delta=\frac{\overline{\mathrm{V}}_{1}-\overline{\mathrm{V}}_{2}}{\sqrt{\frac{\sigma_{1}}{\mathrm{~N}_{1}}+\frac{\sigma_{2}}{\mathrm{~N}_{2}}}}=\frac{4,49-2,06}{\sqrt{\frac{(1,85)^{2}}{59}+\frac{(1,17)^{2}}{69}}}=8,7
$$

Como o limite de $1 \%$ é 2,58, é evidente que esse resultado é altamente significativo o que demonstra a eficácia daquele éster em inlbir a brotação das batatinhas. 
Podíamos também ter feito a análise estatística do tamanho das brotos dos dois lotes. Allás, isso iria confirmar, plenamente, os resultados obtidos em relação ao número de brotas. O tamanho dos brotos, no lote testemunha, variava de $1 \mathrm{~cm}$. a 12, com uma média de $5 \mathrm{cms}$., enquanto que no lote tratado, êste variava de $0 \mathrm{~cm}$., em àlgumas batatas e $3 \mathrm{cms}$., com uma média de $1,4 \mathrm{cms}$.

Os resultados, como vemos, são concludentes.

\section{PODEM-SE APROVEITAR OS TUBRRCULOS TRATADOS PARA SEMENTES?}

Procuramas, ainda, descobrir até quando perdurava a açăo daquele éster e se o mesmo tinha alguma influência na diminuiçăo da produçáo no caso de tubérculos tratados serem aproveitados para sementes. Para isso, plantamas em dois canteiras da Horta de nossa Secçá, 140 tubérculos de batatas tratadas e o mesmo número de testemunhas.

Dividimos os canteiros pelo melo, plantando em cada, a metade das batatas tratadas e das testemunhas, alternando os lotes. Isso fol feito no dia 13-9-948. Os mesmos cuidados culturais foram dispensados aos dois lotes.

Conquanto notássemos diferenças nos dois lotes quanto ao desenvolvimento vegetativo e florescimento, năo nos interessamas por êsses fatos, pois o nasso fito era a produçăo.

Em 27-12-948, quando a parte aérea de todos os lotes estava completamente seca, realizamos a colheita.

Os lotes tratados produziram 43,600 quilos. Os lotes testemunhas produziram 81,400 quilos.

Isso nos dá uma médła por planta originada de tubérculo tratado de 0,311 kgs. A média das testemunhas foi de 0,581 kgs. Como se vê, há de fato, uma notável influência diminuidora da produção, de quase metade. Talvez um tratamento mais antecipado ou menos concentrado, năo tenha efeito tăo marcante. Notamas, ainda, na colheita do lote tratado, um sensivel aumento $(2,5 \%)$ de apodrecimento em relação ao lote testemunha. 
Comprovamos também o fato de que os tubérculos tratados com o éster metílico do ácido alfanaftalenoacético não têm suas qualidades prejudicadas quando destinados à alimentação.

\section{CONCLUSOES}

Dos resultados obtidos e observações feitas, concluimos o seguinte :

I -Que o éster métílico do ácido alfa-naftalenoacético tem, de fato, ação inibidora sôbre a brotação da batatinha, na concentração utilizada de uma grama de éster para 70 kgs. de batatas.

II - Não houve elevação da percentagem de apodrecimento no lote de batatinhas armazenadas que foram tratadas com o éster, se bem que na colheita apresentassem 2,5\% de apodrecimento.

III - A melhor época para se fazer o tratamento será objeto de novas experiências. Talvez um tratamento um pouco mais cedo evite ainda mais a brotação prejudicial.

IV - O éster é inofensivo ao homem, mesmo em percentagens mais elevadas.

V - Não se devem aproveitar para sementes os tubérculos tratados, pois a produção é bastante diminuida. 



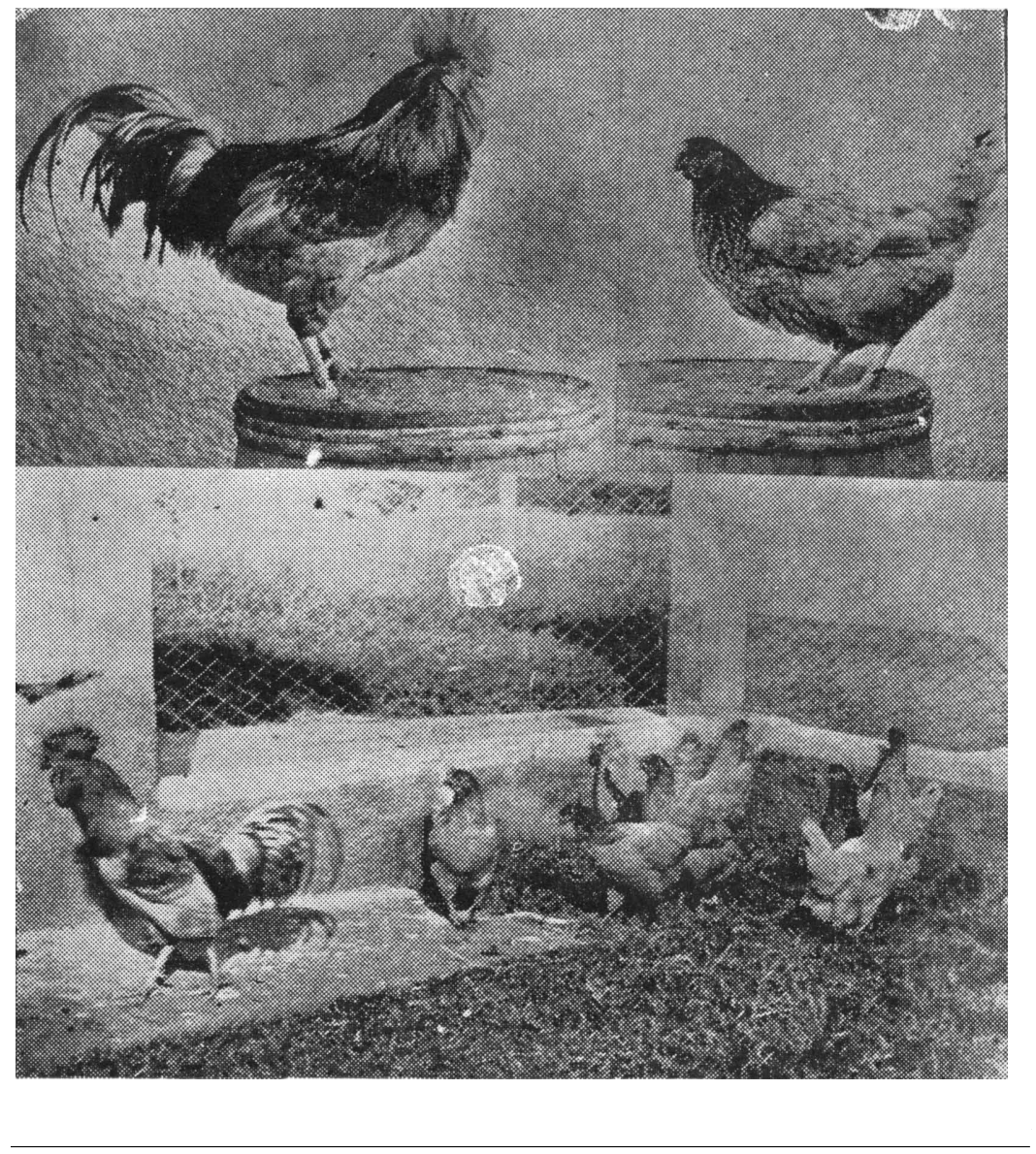

Em cima : Galo e galinha de plumagem azul

Galinha de ovos azuis

Em baixo : Parque com galinhas de ovos azuis

Observe uma galinha preta no lado direito da figura 